\title{
ANALISIS PENGARUH GAYA KEPEMIMPINAN TRANSFORMASIONAL, POLA KOMUNIKASI DAN MANAJEMEN KONFLIK TERHADAP KEPUASAN KERJA KARYAWAN
}

\author{
Meita Pragiwani $^{1}$, Aditya Surya Lesmana ${ }^{2}$, Mohammad Benny Alexandri ${ }^{3}$ \\ ${ }^{1,2}$ Sekolah Tinggi Ekonomi Indonesia (STEI) \\ ${ }^{3}$ Universitas Padjadjaran \\ ola_168@yahoo.com¹, adityasuryalesmana@gmail.com², bennyalexandri@yahoo.co.id ${ }^{3}$
}

\begin{abstract}
ABSTRAK
Penelitian ini bertujuan untuk mengetahui seberapa besar pengaruh gaya keemimpinan ransformasional, pola komunikasi, dan manajemen konflik terhadap kepuasan kerja karyawan. Strategi penelitian ini adalah strategi asosiatif.

Metode pengumpulan data yang digunakan dalam penelitian ini adalah survei sampel, dimana peneliti membagikan kuesioner untuk mengumpulkan data. Populasi dalam penelitian ini adalah karyawan PT Bank Maybank Indonesia Tbk Cabang Area Juanda Jakarta berjumlah 60. Sampel dalam penelitian ini diambil dengan menggunakan rumus slovin dengan tingkat eror $(\mathrm{e})=5 \%$, Dengan demikian jumlah sampel yang digunakan untuk penelitian ini berjumlah 52 karyawan.

Hasil penelitian menunjukan, pengaruh positif gaya kepemimpinan transformasional terhadap kepuasan kerja karyawan sebesar 0,294 atau 29,4\% dan signifikan, pengaruh positif pola komunikasi terhadap kepuasan kerja karyawan sebesar 0,343 atau 34,3\% dan signifikan, pengaruh positif manajemen konflik terhadap kepuasan kerja karyawan sebesar 0,334 atau 33,4 \% dan signifikan.
\end{abstract}

\section{Kata Kunci: Gaya Kepemimpinan Transformasional, Pola Komunikasi, Manajemen Konflik, Kepuasan Kerja Karyawan}

\section{ABSTRACT}

This study aims to determine how much influence the informational leadership style, communication patterns, and conflict management on employee job satisfaction. This research strategy is an associative strategy. The data collection method used in this study is a sample survey, where researchers distribute questionnaires to collect data. The population in this study were employees of PT Bank Maybank Indonesia Tbk Juanda Area Jakarta Branch totaling 60. The sample in this study was taken using the Slovin formula with an error rate $(e)=5 \%$, Thus the number of samples used for this study amounted to 52 employees. The results showed, the positive influence of transformational leadership style on employee job satisfaction of 0.294 or $29.4 \%$ and significant, positive influence of communication patterns on employee job satisfaction of 0.343 or $34.3 \%$ and significant, positive effect of conflict management on employee job satisfaction of 0.334 or $33.4 \%$ and significant.

Keywords: Transformational Leadership Style, Communication Patterns, Conflict Management, Employee Job Satisfaction. 


\section{PENDAHULUAN}

\section{Latar Belakang}

Di Indonesia, semua Jasa Perbankan dan Non-Perbankan dibawah pengawasan Otoritas Jasa Keuangan (OJK), Otoritas Jasa Keuangan adalah lembaga Negara yang dibentuk berdasarkan undang-undang Nomor 21 Tahun 2011 yang berfungsi menyelenggarakan sistem pengaturan dan pengawasan yang terintegrasi terhadap keseluruhan kegiatan di dalam sektor jasa keuangan baik di sektor perbankan, pasar modal, dan sektor jasa keuangan non-bank seperti Asuransi, Dana Pensiun, Lembaga Pembiayaan, dan Lembaga Jasa Keuangan lainnya.

PT. Bank Maybank Indonesia, Tbk adalah salah satu bank swasta terkemuka di Indonesia yang merupakan bagian dari grup Malayan Banking Berhad (Maybank), salah satu grup penyedia layanan keuangan terbesar di ASEAN. Sebelumnya, Maybank Indonesia bernama PT. Bank Internasional Indonesia Tbk (BII) yang didirikan pada 15 Mei 1959 mendapatkan izin sebagai bank devisa pada tahun 1988 dan mencatatkan sahamnya sebagai perusahaan terbuka di Bursa Efek Jakarta dan Surabaya (sekarang telah merger menjadi Bursa Efek Indonesia) pada tahun 1989.

Menurut data Forbes (2019) dan menurut media CNN Indonesia (2018) menyatakan bahwa Bank Maybank Indonesia merupakan bank terbesar ke-4 (empat) di Asia Tenggara dan Bank Maybank Indonesia berada di peringkat 9 di Indonesia. Hal tersebut dikarenakan Maybank Indonesia menyediakan serangkaian produk dan jasa komprehensif bagi nasabah individu maupun korporasi melalui layanan Community Financial Services (Perbankan Ritel dan Perbankan
Non-Ritel) dan Perbankan Global, serta pembiayaan otomotif melalui entitas anak yaitu WOM Finance untuk kendaraan roda dua dan Maybank Finance untuk kendaraan roda empat. Maybank Indonesia juga terus mengembangkan layanan dan kapasitas digital banking melalui Mobile Banking, Internet Banking, Maybank2U (mobile banking berbasis internet banking dan berbagai saluran lainnya).

PT. Bank Maybank Indonesa Tbk Cabang Area Juanda Jakarta membawahi 7 (tujuh) Kantor Cabang Pembantu (KCP) yang mana masing-masing Kantor Cabang Pembantu (KCP) memiliki gaya kepemimpinan, pola komunikasi, serta manajemen konflik yang terjadi pada masing-masing kantor cabang tentu berbeda-beda. Meskipun memiliki gaya kepemimpinan, pola komunikasi, dan manajemen konflik yang berbeda namun semua harus mengacu pada SOP (Standar Operasional Prosedur) yang telah ditetapkan oleh PT. Maybank Indonesia Tbk yang akan menciptakan kepuasan kerja karyawan.

PT. Bank Maybank Indonesia Tbk memiliki nilai perusahaan (core value) yang disebut sebagai TIGER. Di dalam nilai TIGER tersebut terdapat makna $\mathrm{T}$ yang memiliki arti “Team Work" yang harus dijalankan dengan penuh profesional dan rasa tanggung jawab. Arti “Team Work” yaitu:

1. Memperlakukan orang lain dengan adil dan penuh hormat,

2. Membangun rasa percaya satu dengan yang lainnya,

3. Berkomitmen pada sasaran bersama,

4. Membangun struktur tim yang efektif (peran, tanggung jawab, dsb.), 
5. Memperkuat semangat tim,

6. Menghormati perbedaan pendapat dan gagasan,

7. Terbuka dan mau menerima feedback,

8. Berani dalam mengambil tindakan, membuat keputusan, dan menetapkan prioritas tim.

Sebagai seorang atasan (Service Manager) harus dapat melakukan hal tersebut agar terciptanya kepuasan kerja karyawan pada masing-masing kantor cabang PT Bank Maybank Indoensia Tbk Cabang Area Juanda Jakarta. Akan tetapi, masih terdapat seorang Service Manager (SM) yang tidak menjalankannya dengan penuh rasa tanggung jawab. Hal ini tentunya sangat bertentangan dengan nilai TIGER yang telah dibuat oleh PT. Bank Maybank Indonesia Tbk.

Menurut Edy Sutrisno (2014: 166) faktor kepuasan kerja karyawan harus diperhatikan oleh perusahaan, perusahaan harus mengetahui tingkat kepuasan kerja karyawannya, jika kepuasan kerja seorang karyawan rendah maka produktifitas kerja mereka pun rendah. Maka dari itu perusahaan harus terus melakukan evaluasi guna menjaga kepuasan kerja karyawannya.

\section{Rumusan Masalah}

Spesifikasi masalah pokok pada penelitian ini adalah sebagai berikut:

1. Apakah Gaya Kepemimpinan Transformasional berpengaruh langsung terhadap Kepuasan Kerja Karyawan?

2. Apakah Pola Komunikasi berpengaruh langsung terhadap Kepuasan Kerja Karyawan?

3. Apakah Manajamen Konflik berpengaruh langsung terhadap Kepuasan Kerja Karyawan?

\section{KAJIAN PUSTAKA}

\section{Kepemimpinan}

Kepemimpinan didefinisikan sebagai proses dimana seorang individu membimbing orang lain dalam kegiatan kolektif mereka, dengan cara mengatur, mengarahkan, mengkoordinasikan, mendukung, dan memotivasi usaha mereka (Forsyth: 2010).

Kepemimpinan merupakan faktor terpenting dalam suatu organisasi. Menurut Stogdi dalam Dr. M. Sobry Sutikno (2014: 15), terdapat hampir sama banyaknya definisi tentang kepemimpinan dengan jumlah orang yang telah mencoba mendefinisikannya. Stogdill menyatakan bahwa kepemimpinan sebagai konsep manajemen dapat dirumuskan dalam berbagai macam definisi tergantung dari mana titik tolak pemikirannya.

Berdasarkan beberapa pengertian diatas yang digunakan landasan dalam penelitian ini adalah pendapat Yukl (2010), yang mengatakan bahwa kepemimpinan berkaitan dengan proses yang disengaja dari seseorang untuk menekankan pengaruhnya yang kuat terhadap orang lain untuk membimbing, membuat struktur, memfasilitasi aktivitas dan hubungan di dalam kelompok atau organisasi.

Walaupun begitu, gaya kepemimpinan tidak ada yang semuanya baik dan tidak ada yang semuanya buruk. Gaya kepemimpinan memiliki kelebihan dan kekurangnnya masing-masing. Gaya kepemimpinan yang baik atau buruk ditentukan dari situasi yang dihadapi oleh setiap pemimpin. Hal yang terpenting adalah bagaimana gaya kepemimpinan yang dimiliki oleh setiap pemimpin dapat dimanfaatkan untuk mencapai tujuan dari organisasi. 
Menurut Modiani (2014: 47), gaya kepemimpinan transformasional merupakan kemampuan untuk memberikan inspirasi dan memotivasi para pengikutnya untuk mencapai hasilhasil yang lebih besar dari pada yang direncanakan secara orisinil dan untuk imbalan internal.

Komunikasi adalah suatu aktifitas yang kompleks dan menantang dan bukanlah suatu aktifitas yang mudah, pencapaian kompetensi komunikasi memerlukan pemahaman dan suatu keterampilan sehingga komunikasi yang kita lakukan menjadi efektif (Ruben dan Stewart, 2013: 3).

\section{Manajemen Konflik}

Manajemen adalah pengelolaan sumber daya secara efektif untuk mencapai suatu sasaran. Robbins dan Coulter (2014) mengemukakan manajemen melibatkan koordinasi dan mengawasi aktivitas kerja orang lain agar mereka dapat menyelesaikan pekerjaannya dengan efektif dan efisien. Sedangkan Griffin (2012) mendefinisikan manajemen sebagai suatu rangkaian aktivitas (termasuk perencanaan dan pengambilan keputusan, pengorganisasian, kepemimpinan, dan pengendalian) yang diarahkan pada sumber-sumber daya organisasi (manusia, keuangan, fisik, dan informasi) dengan maksud untuk mencapai tujuan organisasi secara efektif dan efisien. Manajemen dalam suatu organisasi adalah suatu hal yang penting agar organisasi dapat berjalan dengan baik dan tercapainya tujuan organisasi. Tugas manajemen dalam suatu organisasi dilakukan oleh seorang manajer. Manajer adalah seseorang yang menyelesaikan suatu pekerjaan melalui orang lain (Robbins dan Judge, 2015).
Menurut Wirawan (2010) manajemen konflik merupakan proses pihak-pihak yang terlibat konflik atau pihak ketiga dalam menyususn strategi konflik dan menerapkannya untuk mengendalikan konflik agar menghasilkan resolusi yang diinginkan. Manajemen konflik juga berarti proses dimana manajer dalam organisasi memutuskan metode yang tepat untuk mengelola konflik (Mukhtar, 2013). Sedangkan menurut Faure dan Rubin dalam Opute (2014) mendefinisikan manajemen konflik sebagai proses dimana salah satu pihak mencoba untuk menegosiasikan secara nyata atau membayangkan perbedaan dalam penyelesaian konflik yang dapat diterima bersama.

Kepuasan kerja adalah sebagai suatu sikap umum seseorang individu terhadap pekerjaannya. Kepuasan kerja adalah suatu perasaan positif tentang pekerjaan yang dihasilkan dari suatu evaluasi dari karakteristik-karakteristiknya (Robbins \& Judge, 2015: 46).

Kepuasan kerja karyawan pada dasarnya merupakan ekspresi bagaimana perasaan seseorang atas pekerjaan dan berbagai aspek lain dari pekerjaannya. Dengan kata lain, kepuasan kerja merupakan sikap seseorang terhadap pekerjaannya (Brahmana dan Christina, 2010).

Menurut Handoko (2015: 109) ada dua faktor yang mempengaruhi kepuasan kerja, yaitu:

1) Faktor Pegawai, yaitu kecerdasan (IQ), kecakapan khusus, umur , jenis kelamin, kondisi fisik, pendidikan, pengalaman kerja, masa kerja, kepribadian, emosi, cara berfikir, persepsi, dan sikap kerja.

2) Faktor Pekerjaan, yaitu jenis pekerjaan, struktur organisasi, pangkat (golongan), kedudukan, mutu 
pengawasan, jaminan finansial, kesempatan promosi jabatan, inteaksi social, dan hubungan kerja.

Berdasarkan uraian tersebut dapat disimpulkan bahwa kepuasan kerja karyawan merupakan sebuah perasaan senang atau kecewa yang dirasakan oleh seseorang terhadap kinerjanya di perusahaan tempat ia bekerja.

Kesimpulannya bahwa gaya kepemimpinan trasnformasional adalah suatu cara yang digunakan oleh seorang pemimpin untuk memotivasi, membimbing, dan menginspirasi dalam mengarahkan tujuan yang telah ditetapkan perusahaan yang akan berdampak pada meningkatnya motivasi kerja pengikutnya dan nantinya akan berdampak pada kepuasan kerja karyawan.

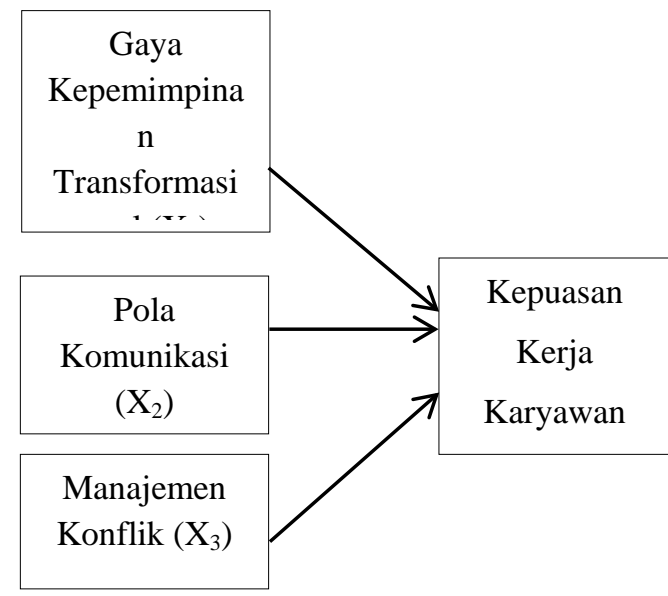

Gambar 2.1

Kerangka Konseptual

\section{METODE PENELITIAN}

Dalam penelitian ini, strategi asosiatif digunakan untuk menjelaskan tentang pengaruh antara variabel gaya kepemimpinan transformasional (X1), pola komunikasi (X2), dan manajemen konflik (X3) terhadap kepuasan kerja karyawan (Y) yang terjadi pada PT. Bank Maybank Indonesia Tbk area Juanda Jakarta baik secara parsial maupun simultan.

Jumlah sampel yang digunakan untuk penelitian ini minimal 52 orang karyawan PT. Bank Maybank Indonsia Tbk cabang area Juanda Jakarta. Adapun kriteria sampel yang digunakan dalam penelitian ini adalah seluruh karyawan PT. Bank Maybank Indonesia Tbk cabang area Juanda Jakarta sebanyak 7 kantor cabang dari divisi operasional yang terdiri dari Teller dan Customer Service sebanyak 50 karyawan dan dari divisi marketing sebanyak 10 karyawan

Analisis data dalam penelitian ini dilakukan dengan menggunakan PLS (Partial Least Square) dan data diolah dengan menggunakan program Smart PLS 3.0. Menurut Ghozali dan Latan (2015:7) model pengukuran PLS terdiri dari model pengukuran (outer model), kriteria Goodness of fit (GoF) dan model struktural (inner model). PLS bertujuan untuk menguji hubungan prediktif antar konstruk dengan melihat apakah ada pengaruh atau hubungan antar konstruk tersebut.

Penilaian Varian Konstruktor Independen (R2)

Menurut Ghozali dan Latan (2015: 78) nilai R-Square $0,75, \quad 0,50$ dan 0,25 menunjukkan model kuat, moderate dan lemah. Berdasarkan tabel 4.8 diatas diperoleh nilai R-Square sebesar 0,767, hal ini menunjukkan bahwa variabel konstruk kepuasan kerja karyawan dapat dijelaskan oleh variabel konstruk gaya kepemimpinan transformasional, pola komunikasi, dan manajemen konflik sebesar $76,7 \%$ sedangkan sisanya dijelaskan oleh variabel lain yang tidak termasuk dalam penelitian ini.

\section{Hasil Penelitian dan Pembahasan}




\section{HASIL PENELITIAN DAN PEMBAHASAN}

\section{Analisis Deskriptif}

Hasil pengujian pengaruh gaya kepemimpinan transformasional, pola komunikasi, dan manajemen konflik terhadap kepuasan kerja karyawan pada PT. Bank Maybank Indonesia Tbk area Juanda Jakarta menunjukkan bahwa:

1. Variabel Gaya Kepemimpinan Transformasional (X1) berpengaruh positif terhadap Kepuasan Kerja Karyawan (Y). Hal ini juga di dukung oleh penelitian yang dilakukan oleh Yunita Puspa Dewi, Diana Sulianti K Tobing, Sri Wahyu Lelly Hana Setyanti (2018) yang menunjukkan bahwa gaya kepemimpinan transformasional memiliki pengaruh langsung terhadap kepuasan kerja karyawan.

2. Variabel Pola Komunikasi (X2) berpengaruh positif terhadap Kepuasan Kerja Karyawan (Y). Hal ini juga di dukung oleh penelitian yang dilakukan oleh Delisius Habri Putra Makutika, Adolfina, dan Yantje Uhing (2018) yang menunjukkan bahwa gaya kepemimpinan transformasional, kesejahteraan dan komunikasi berpengaruh langsung secara simultan dan secara parsial terhadap kepuasan kerja karyawan.

3. Variabel Manajemen Konflik (X3) bepengaruh positif terhadap Kepuasan Kerja Karyawan (Y). Hal ini juga didukung oleh penelitian yang dilakukan oleh Chen Han dan I Gusti Salit Ketut Netra (2014) yang menunjukkan bahwa manajemen konflik berpengaruh positif terhadap kepuasan kerja karyawan.

Gaya kepemimpinan transformasional berpengaruh langsung terhadap kepuasan kerja karyawan.

Di dalam dunia perbankan saat ini, kebanyakan menerapkan sistem gaya kepemimpinan transformasional yang memiliki pengertian bahwa seorang pemimpin lebih memperjelas peran dan tugas karyawannya dengan cara membimbing dan memotivasi mereka pada arah dan tujuan yang telah ditetapkan oleh perusahaan. Oleh karena itu, manajer harus dapat mendorong karyawan agar tetap produktif dalam mengerjakan tugastugas dan tanggung jawabnya masingmasing sehingga dapat menimbulkan kepuasan dalam diri karyawan.

Pola komunikasi berpengaruh langsung terhadap kepuasan kerja karyawan.

Pemimpin memegang peran penting di dalam sebuah perusahaan dan pengelolaannya dalam beroperasionya perusahaan tersebut. Pemimpin juga membantu para karyawannya dalam menyelesaikan dan mencari jalan keluar setiap ada complain dari nasabah. Pimpinan juga mempunyai pengetahuan luas dalam bidang tugasnya, keinginan untuk mencapai sesuatu serta adanya toleransi dan sikap bersahabat kepada para bawahnnya diluar dari organisasi dan mampu menempatkan diri pada saat jam bekerja dan pada saat sedang diluar jam bekerja yang akan membuat bawahan merasa puas.

Manajemen konflik berpengaruh langsung terhadap kepuasan kerja karyawan.

Menjadi seorang pemimpin memegang peran penting di dalam sebuah perusahaan dan pengelolaannya di dalam sebuah konflik. Hal ini dapat dilihat dari pemimpin yang sigap dalam mengelola konflik dan mengatasi permasalahan yang terjadi di dalam perusahaan. Pemimpin juga membantu para karyawannya dalam menyelesaikan dan mencari jalan keluar setiap terjadi permasalahan di dalam perusahaan. Pimpinan juga harus adil dalam menyelesaikan masalah, tidak membedakan atau berpihak kepada siapapun agar tidak terjadi kesenjangan dan perbedaan satu dengan yang lainnya sehingga membuat kepuasan karyawan dalam bekerja. 


\section{KESIMPULAN DAN SARAN}

Berdasarkan hasil penelitian dan pembahasan, maka peneliti ingin memberikan saran yang dapat dijadikan masukan kepada PT. Bank Maybank Indonesia Tbk cabang Area Juanda Jakarta, yaitu:

1) Gaya kepemimpinan transformasional di PT Bank Maybank Indonesia Tbk cabang Area Juanda Jakarta sudah baik dimana pemimpin senantiasa untuk mendorong karyawan agar bekerja lebih baik dan mendorong karyawan untuk berinovasi dalam menyelesaikan masalah. Namun demikian, tetap perlu diperhatikan dalam memperlakukan bawahan dengan adil agar tidak terjadi kesenjangan satu dengan yang lainnya.

2) Pola komunikasi di PT Bank Maybank Indonesia Tbk cabang Area Juanda Jakarta sudah baik dimana pemimpin memberikan instruksi mengenai pekerjaan kepada bawahannya selain itu komunikasi antar rekan satu tim dalam mengkoordinasikan tugas-tugas yang dijalani berjalan dengan baik. Namun demikian, tetap perlu diperhatikan komunikasi antar rekan satu tim dalam pemecahan konflik yang terjadi dan perlu ditingkatkan lagi kegiatan bersama yang dilakukan diluar jam kantor.

3) Manajemen konflik di PT Bank Maybank Indonesia Tbk cabang Area Juanda Jakarta sudah baik dimana pemimpin memberikan tugas dengan jelas kepada bawahannya, dan pemimpin yang memiliki pendidikan yang tinggi dan pengalaman yang mumpuni. Namun demikian, tetap perlu diperhatikan dalam penggunaan bahasa yang mudah difahami dan tidak bertele-tele dalam memecahkan suatu masalah yang terjadi.
4) Kepuasan kerja karyawan di PT Bank Maybank Indonesia Tbk cabang Area Juanda Jakarta sudah baik dimana sikap pemimpin yang disukai oleh bawahannya dan pemimpin yang memberikan motivasi kepada bawahannya. Namun demikian, tetap perlu diperhatikan dalam memberikan kompensasi yang bersifat tidak langsung bagi karyawan yang telah melakukan upaya lebih dalam bekerja, serta memberikan lingkungan kerja yang kondusif agar terciptanya kepuasan kerja karyawan di PT Bank Maybank Indonesia Tbk Area Juanda Jakarta.

\section{DAFTAR PUSTAKA}

Amri, K. 2017. Analisis Pertumbuhan Ekonomi dan Ketimpangan Pendapatan: Data Panel 8 Provinsi di Sumatera. Jurnal EMT KITA, 1 (1), 1-11.

Artana, I Wayan Arta. 2012. Pengaruh Kepemimpinan, Kompensasi, dan Lingkungan Kerja Terhadap Kinerja Karyawan (Studi Kasus di Maya Ubud Resort \& Spa). Jurnal Perhotelan dan Parwisata, 2(1), 68-69.

As'ad, Mohammad. 2014. Seri Ilmu Sumber Daya Manusia: Psikologi Industri, Edisi IV. Yogyakarta: Liberty.

Brahmana, Sunardi S., dan Christina, Veronica. 2010. Dampak Kepuasan Kerja Pada Komitmen Organisasi Dosen dan Karyawan Administrasi Universitas Widyatama. Penelitian UPPM.

CNN Indonesia. 2019. 10 Bank Besar. https://www.cnnindonesia.com/ekonomi /20190201161251-78-365751/bankbtpn-geser-dua-pemain-lawas-masukdaftar-10-bank-besar.

Forsyth, D. R. 2010. Group Dynamic. Belmont: Cenggage Learning, Fromm E.

Ghozali, Imam dan Hengky Latan. 2015. Partial Least Square Konsep, Teknik dan Aplikasi Menggunakan SmartPLS 
3.0 Edisi 2. Semarang. Badan Penerbit UNDIP.

Griffin, Ricky W. 2012. Management. Eleventh Edition. United States: Cengage Learning.

Handoko, T. Hani 2015. Manajemen Personalia dan Sumber Daya Manusia, (Cetakan ke Delapan Belas). Yogyakarta: BPFE.

Hopkins, M.M, dan Yonker, R.D. 2015. Managing Conflict With Emotional Intelligence: Abilities That Make A Difference. Journal Of Management Development, 226-244.

Kamus Besar Bahasa Indonesia. 2019. Bank. https://kbbi.web.id/bank.

Kasmir. 2015. Dasar-Dasar Perbankan. Jakarta: PT. Raja Grafindo Persada.

Maybank Indonesia. 2019. Tentang Maybank Indonesia.

https://www.maybank.co.id/corporateinf ormation

Muhammad, Arni. 2013. Komunikasi Organisasi. Jakarta: Bumi Aksara.

Mukhtar, S.A. 2013. Organizational Conflict Management Strategies On Employee Job Satisfaction: A Conceptual Relationship. International Journal Of Mangement Research And Review, 2855-2862.

Modiani, Tria. 2014. Pengaruh Kepemimpinan Transformasional, dan Kompensasi Terhadap Kinerja Karyawan PT. PLN (Persero) UPJ Semarang. Jurnal Administrasi Bisnis. Vol.1, No.1.

Nursiana, Adinoto. 2016. Pengaruh Internet Banking, Kualitas Pelayanan, Reputasi Produk, Lokasi terhadap Loyalitas Nasabah dengan Intermediasi Kepuasan Nasabah. Jurnal Keuangan dan Perbankan. Vol. 19, No.3.

Opute, A.P. 2014. Cross-Functional Bridge In Dyadic Relationship: Conflict Management And Performance Implications. Team Performance Management, 121-147.
Pranit, K. 2010. Orgaizational Behavior. New Delhi: Gennext Publication.

Priansa, Donni Juni. 2014. Perencanaan dan Pengembangan SDM. Jakarta: Alfabeta.

Rahman, Fauzie. et al. 2017. Perilaku Organisasi. Banjarbaru: Expert.

Rizal, Syamsul dan Munawir. 2017. Pengaruh Kepuasan Nasabah Terhadap Menggunakan Mobile Banking (MBanking) pada Bank BCA Cabang Banda Aceh. Jurnal Ekonomi dan Manajemen Teknologi (EMT), 1(2), 6878.

Robbins, S. dan Timothy A J. 2010. Perilaku Organisasi. Edisi ke-16. Jakarta: Salemba Empat.

Robbins, P. Stephen dan Mary Coulter. 2014. Management. Twelfth Edition. United States: Pearson Education Limited.

Robbins, Stephen P dan Judge, Timothy A. 2015. Organizational Behavior Edition 15. New Jersey: Pearson Education.

Ruben, Brent D dan Stewart, Lea P. 2013. Komunikasi dan Perilaku Manusia. Jakarta: Rajawali Pers.

Saeed, T., Almas, S., Anis Ul-Haq, M., dan Niazi. 2014. Leadership Styles: Relationship With Conflict Management Styles. International Journal Of Conflict Management, 25 (3), 214-215.

Santos, Rudi. 2013. Kelembagaan Perbankan, Jakarta: Gramedia.

Sitompul, Ade Florent S. 2010. Pengarh Manajemen Konflik Terhadap Kinerja Karyawan pada Karyawan PT. PLN (Persero) Cabang Medan. Skripsi tidak diterbikan. Fakultas Ekonomi Universitas Sumatera Utara.

Spaho, K. 2013. Organizational Communication And Conflict Management. Management. 18(1), 103118.

Stanley, Senewe 2009. Kepemimpinan Transformasional dan Organization Citizenship Behavior Dampaknya Terhadap Kinerja Pegawai KPKNL Provinsi Sulawesi Utara. Jurnal EMBA, 1(3), 356-365. 
Stanton, William J. 2010. Prinsip Pemasaran. Edisi VII. Jakarta: Erlangga.

Sugiyono. 2015. Metode Penelitian Kualitatif, Kuantitatif, dan K ombinasi (Mixed Methods). Bandung: Alfabeta.

Sugiyono. 2017. Metode Penelitian Kualitatif, Kuantitatif, dan K ombinasi (Mixed Methods). Bandung: Alfabeta.

Sutikno, Sobry M. 2014. Pemimpin dan Gaya Kepemimpinan. Edisi Pertama. Lombok: Holistica.

Sutrisno, Edy. 2014. Manajemen Sumber Daya Manusia (cetakan ke enam). Jakarta: Kencana Pranada Media Grup.

Wikipedia Indonesia. 2019. Otoritas Jasa Keuangan

(OJK). https://id.wikipedia.org/wiki/Otoritas _Jasa_Keuangan.

Winardi. 2012. Kepemimpinan Dalam Manajemen. Jakarta: Rineka Cipta.

Wirawan. 2010. Konflik dan Manajemen Konflik: Teori, Aplikasi, dan Penelitian. Jakarta: Salemba Humanika.

Yukl, Gary. 2010. Kepemimpinan Dalam Organisasi. Penerjemah: Budi Supriyanto, Jakarta: PT. Indeks.

Jurnal :

Chen Han dan I Gusti Salit Ketut Netra (2014) dalam E-Jurnal Manajemen Vol. 3 No. 82014.

D. I Gst Agung Rai Cahyadi Putra dan Ni Wayan Mujiati (2015) dalam E-Jurnal Manajemen Unud, Vol. 4, No.5, 2015: 1322-1335 ISSN: $2302-8912$.

Delisius Habri Putra Makutika, Adolfina, dan Yantje Uhing (2018) dalam Jurnal EMBA, Vol. 6 No. 4 September 2018, Hal. 3473 - 3482 ISSN: 2303-1174.

Dimitros Belias, Athanasios Koustelios, Labros Sdrolias, dan George Aspridis (2015) dalam Procedia - Social and Behavioral Sciences 175 (2015) 324 -
333 yang berjudul "Job Satisfaction, Role Conflict, and Authonomy of Employees in The Greek Banking Organizations”.

Dr. Vikas Chaddha (2016) dalam Splint International Journal of Professionals Vol. 3, Issue: 6, Juni 2016 ISSN: 2349 6045.

Farisa Nuril Amaliyah, Bambang Swasto, Heru Susilo (2014) dalam Jurnal Administrasi Bisnis (JAB) Vol. 14 No.1 September 2014.

Mahmoud Kamal Abouraia dan Saad Mohammed Othman (2017) dalam American Journal of Industrial and Business Management, 2017, 7, 404 423 ISSN: 2164 - 5175.

Yunita Puspa Dewi, Diana Sulianti K Tobing, Sri Wahyu Lelly Hana Setyanti (2018) dalam JURNAL EKONOMI 14 (1), 50 - 67 Vol. 1 (2018). 